\title{
Immigration and Natives' Wages: Understanding Their Correlation in the 1980s
}

\author{
Todd Easton*
}

Abstract: Major papers on immigration's wage impacts in the 1980s concluded that immigration into the U.S. modestly reduced the wages of natives. Authors based these conclusions on fixed-effects models that controlled for area-specific shocks. Without those fixed effects, however, these authors found positive correlations between immigration and wages. This study examines two specific shocks that might explain this counterintuitive result: changes in the industry structure of labor demand and differences in inflation rates among metropoli$\tan$ areas. The study finds no evidence that the first shock matters for understanding immigration, but finds that a large proportion of the positive correlation between immigration and wages disappears if one controls for differences in inflation rates.

\section{INTRODUCTION}

Restructuring of the U.S. economy has particularly stung Americans with lower levels of education. The loss of well-paying manufacturing jobs, along with other factors, substantially reduced average earnings of people in this group-and much of the decline happened in the 1980s. For example, the average real wage of male high school graduates declined by $\$ 1.83$ between 1979 and 1989; the decline for females was $\$ .27$. In contrast, the decline in high school graduates' real wages between 1989 and 1997 was much less, $\$ .70$ for men and $\$ .06$ for women. ${ }^{1}$

One possible contributor to the plight of people with lower education levels is international immigration. Among recent immigrants, the representation of workers with a high school education or less exceeds that among natives. If immigrants and natives were substitutes for one another, one would expect immigration to cause declines in relative wages for less-educated natives. Even immigrants with more than a high school education might compete for jobs with lesseducated natives, since lack of connections, lack of credentials recognized in the U.S., and lack of fluent English may limit their job options.

In spite of this expectation, direct evidence that immigrants substantially reduce the wages earned by any group of natives is scarce. The evidence we have comes from studies that regress wage levels of native workers on their personal characteristics and on measures of immigration into, or immigrant presence in, the area where the natives work. In an even-handed review of these studies,

*Associate Professor, Dr. Robert B. Pamplin, Jr. School of Business Administration, University of Portland, Portland, OR. Thanks to Laura Connolly, Mary King, and Brent Moulton for helpful suggestions. Thanks to Maria Enchautegui and to the Consortium for International Earth Science Information Network for data.

${ }^{1}$ All wages are expressed in 1997 dollars and deflated using the CPI-U-X1 deflator. Data are from the Economic Policy Institute web site, <http://epinet.org/datazone/downloadlist.html>. 
Borjas (1994) concludes that the elasticity of wages earned by native workers in a metropolitan area with respect to immigration is small and negative (around -.01 to -.02), regardless of the subpopulation of native workers studied.

The studies Borjas (1994) reviewed all examine data that predate the acceleration of immigration in the 1980s. Three careful studies of immigration's more recent effects also reach the conclusion that immigrant inflows reduce wage levels for some groups of native workers (Borjas, Freeman, and Katz 1997; Card 1997, 2001). All these studies estimate metropolitan wages by skill groups and measure immigration into metropolitan areas within the same skill groups. Thus, they can examine immigration's impact both on metropolitan wage levels and on the shape of the metropolitan wage distribution. However, the conclusion that immigration reduces wage levels is based on estimations of wage equations including area fixed effects, an inclusion justified by a desire to control for area-specific shocks that might otherwise obscure immigration's impact on wages. ${ }^{2}$

The inclusion of these controls has a dramatic influence on the coefficients of variables measuring immigrant inflows. Dropping the area fixed effects from wage equations results in coefficients measuring immigrant inflows becoming positive. ${ }^{3}$ Borjas, Freeman, and Katz (1996) find faster wage growth in 1979-89 in areas receiving more immigration during that period. Card (1997) finds higher wage levels in 1989 in areas receiving more immigration in the late 1980s.

To clarify the implications of the regressions with and without area fixed effects, focus for a moment on the Borjas, Freeman, and Katz (1996) study, and think about less-educated workers as a skill group with high levels of immigration. Their regressions with fixed effects suggest that less-educated workers in areas with high levels of immigration by less-educated workers had slower wage growth than better-educated workers in those same areas. This result fits with expectations one might have from economic theory. On the other hand, the regressions without area fixed effects suggest that less-educated workers in areas with high levels of immigration saw faster wage increases than less-educated workers elsewhere. There are two possible explanations for this result. The first is counterintuitive: immigration itself raised metropolitan wage levels. The second is more plausible: some other variable, correlated with immigration, raised metropolitan wage levels and, in estimations without area fixed effects, the omission of this other variable biased the coefficient on the immigration measure upward.

The current paper contributes to the immigration literature by eschewing area fixed effects and examining two area-specific factors that might be raising nominal wages of natives in areas receiving high levels of immigration. Identifying

2The phrase "area fixed effects" in these studies refers to the inclusion of dummy variables that identify each area (metropolitan area, for example) under study.

${ }^{3}$ Card (1997, p. 36) recognizes this explicitly. Only one of six estimations with area fixed effects in Card's 1997 paper have a negative coefficient on the variable measuring immigrant inflows; in that one case the coefficient is small and far from statistical significance. In a substantially reworked version of the same paper, however, Card (2001, p. 57) provides only an indirect admission of the influence of area fixed effects. Borjas, Freeman, and Katz do not present estimations without fixed effects in their 1997 paper. However, they present similar estimations in a 1996 paper, in which none of the coefficients measuring immigrant inflow into an area has a negative sign when area fixed effects are included. 
these factors is important if we wish more confidently to draw conclusions about the relationship between immigration and native wages.

To examine these area-specific factors, this paper estimates metropolitan wage levels for 20 subpopulations of workers (defined by sex, education, experience, and race/ethnicity), focusing its attention on less-educated natives who might be particularly susceptible to immigration's impact. It estimates those wage levels in the late 1980s for a sample of the 86 largest metropolitan areas in the United States. The paper explores two factors that might explain the apparent tendency for overall wage levels to be higher in areas with high levels of immigration. First, it examines exogenous demand shifts, to see if workers in cities with high immigration levels might have benefited coincidentally from changes in the industry structure of labor demand. Second, it explores the effect of differential inflation rates on wages at the metropolitan level to see if faster nominal wage growth in cities with high immigration levels might reflect faster increases in living costs in those cities.

The results of this paper suggest that demand shifts have contributed little to higher wages in metropolitan areas with high levels of immigration. The impact of differential inflation rates, on the other hand, may have been substantial. Inclusion of a variable measuring changes in the price level (in two restricted groups of metropolitan areas) reduced the coefficient of the immigration measure substantially. However, demand shifts and differential inflation rates are not sufficient to explain completely the positive relationship between immigration and metropolitan wage levels.

\section{DATA AND METHOD}

This section discusses the data used for this study and how they compare to data used in other studies on the 1980s. It also compares the dependent variable and the subpopulations studied in this research to those in other studies. Finally, it presents the model of wage determination used in this research and the method of estimating that model.

Most data used for this research were from a subsample of the 5\% Public Use Microdata Sample of the 1990 Census. The subsample was drawn from residents of the 86 largest metropolitan areas in the United States. To keep the sample size manageable, while still achieving precise estimates of key coefficients, sampling rates for the metropolitan areas were adjusted. The larger a metropolitan area, the smaller the proportion of its records included. This strategy resulted in a sample that included about 571,000 natives with wages. Additional data were taken from the Outgoing Rotation Groups of the 1985 and 1986 Current Population Survey (CPS). Wage observations for 114,000 workers in the 86 largest metropolitan areas were used to estimate metropolitan wage levels in 1985.

Most studies of immigration and wages in the 1980s used Census data from 1980 and 1990 to measure changes in metropolitan wage levels over the decade (Borjas, Freeman, and Katz 1996; Enchautegui 1995). Card (2001) used 1990 
Census data to examine the effect of immigration at the end of the 1980s on the shape of a metropolitan area's wage distribution in 1989. This study has the most in common with Card's (2001) study, in that they both use 1990 Census data. It differs from his study by also including CPS data to control for 1985 wage levels and by using a smaller set of metropolitan areas.

This study looks for evidence that immigration between 1985 and 1989 had negative impacts on native wages in 1989. With the exception of three papers by Card (1990, 1997, 2001), most research has examined immigration's impact over periods of a decade or more. This approach left open the possibility that market responses to immigration-for example, domestic migrants' avoiding cities receiving large flows of immigration or firms targeting investment to cities receiving immigration—obscured some of immigration's impact. By looking at a shorter period, this study aims to document immigration's wage impacts before they might be obscured by market responses.

This study looks hardest for negative effects on less-educated, inexperienced workers, since they are the group most likely to find themselves competing with recent immigrants. ${ }^{4}$ It also examines the impact of race/ethnicity and sex. If metropolitan labor markets are segmented to a significant extent by race/ethnicity and sex, the degree to which an individual competes with immigrants may also be influenced by these characteristics. Altonji and Card (1991) found that immigrants cluster, to some extent, in particular industries and occupations, and that race and sex influenced the amount of overlap between native low-skill workers and immigrants.

To seek evidence for immigration affecting wages, one needs a model of wage determination. The standard approach assumes that the wage a person earns depends on individual characteristics: on productivity-related characteristics (like education) and on characteristics that may make an individual subject to discrimination (like race). However, the nominal wage a person earns will also depend on characteristics of his or her local labor market: on the level of demand for labor and on factors affecting labor supply, such as living costs, local amenities, and immigration.

One way to seek evidence for immigration's impact on wages would be to regress individuals' wages on both individual characteristics and on local labor market characteristics. However, Moulton (1986) pointed out that such an approach will likely bias downward the standard errors of the coefficients on the variables measuring metropolitan characteristics. This study avoids this grouped effects problem by adopting a two-stage estimation procedure suggested by Dickens and Katz (1987).

In the first stage of the estimation, individual wages (for the subpopulation of interest) in 1989 are regressed on individual characteristics, along with dummy variables identifying the metropolitan area in which individuals reside.

${ }^{4}$ They are most likely to compete because they are a) more likely to have similar qualifications and b) less likely to migrate internally. At least two studies found that people who have attended college are more likely to migrate than those who have not (Bound and Holzer 2000, Eberts and Stone 1992). 
Regressions are run separately for men and women. In total, regressions are estimated for 20 subpopulations. The independent variables included vary with the composition of the subpopulation being examined; for example, variables measuring race/ethnicity are not included for regressions estimated on the black subpopulation. The first-stage regression run for workers with less than a high school education is as follows:

$$
\begin{aligned}
& \ln \left(\mathrm{W}_{\mathrm{i}}\right)=\mathrm{a}+\mathrm{b}\left(\mathrm{PEXP}_{\mathrm{i}}\right)+\mathrm{c}\left(\mathrm{PEXP}_{\mathrm{i}}^{2}\right)+\mathrm{d}\left(\mathrm{BLK}_{\mathrm{i}}\right)+\mathrm{e}\left(\mathrm{HISP}_{\mathrm{i}}\right)+\mathrm{f}\left(\mathrm{OTH}_{\mathrm{i}}\right)+ \\
& \mathrm{g}_{1}\left(\mathrm{M} 1_{\mathrm{i}}\right)+\mathrm{g}_{2}\left(\mathrm{M} 2_{\mathrm{i}}\right)+\ldots+\mathrm{g}_{85}\left(\mathrm{M} 85_{\mathrm{i}}\right)+\mathrm{u}_{\mathrm{i}} \text {. }
\end{aligned}
$$

The variables in Equation 1 take on the following values:

$\begin{array}{ll}\mathrm{W} & \begin{array}{l}\text { the nominal hourly wage (in 1989) for each of the } \\ \text { individuals in the sample who has wages; }\end{array} \\ \mathrm{PEXP} & =\begin{array}{l}\text { Potential experience (measured as age minus six, less years } \\ \text { of education); }\end{array} \\ \mathrm{BLK} & =\text { a dummy variable, equal to one for African Americans; } \\ \mathrm{HISP} & =\text { a dummy variable, equal to one for Hispanics; } \\ \mathrm{OTH} & =\text { a dummy variable, equal to one for people not African } \\ & \text { American, Hispanic, or white; } \\ \mathrm{M} 1 \text { to M85 = } & 85 \text { dummy variables, one for each of the metropolitan areas } \\ & \text { except for the omitted one; and }\end{array}$

The wage measure utilized begins with wage and salary income in 1989, from the 1990 Census. This is then divided by the product of weeks worked in 1989 and usual hours worked per week in 1989. The Census measure of wage and salary income excludes fringe benefits; ideally, one would use a measure of income that includes fringe benefits. Graves, Sexton, and Arthur (1999) found that fringe benefits as a proportion of wage and salary vary between regions; however, such data are only available at the regional level.

Once individual wage levels are estimated according to Equation 1 for a particular subpopulation, the coefficients of the metropolitan dummy variables provide a measure of 1989 metropolitan wage levels for that group relative to the omitted metropolitan area, corrected for differences in the group's composition among metropolitan areas. In the second stage of the estimation, these coefficients become the dependent variable in a regression using the metropolitan area, rather than the individual, as the unit of analysis.

These measures of 1989 metropolitan wage levels are regressed on a measure of metropolitan wages in 1985 and on a measure of immigration into the metropolitan area between 1985 and 1990. The immigration measure is the variable of interest in this study; a negative coefficient on it would provide evidence that, for a particular subpopulation, immigration damaged native workers' wages. As mentioned earlier, one would ideally like to add to the immigration measure controls for other important differences in labor supply and labor demand among 
metropolitan areas. Unfortunately, most such differences are difficult to measure directly. For example, there are no reliable, nonproprietary measures of living cost differences among metropolitan areas in 1989, at least if one is interested in working with a large sample of metropolitan areas. Instead, this study begins by assuming that pre-immigration wage levels (wage levels in 1985) will be a good control for differences in labor supply and labor demand before immigration. The estimation of metropolitan wage levels in the second stage is as follows:

$$
\hat{g}_{j}=h+i M W G_{j}+k P I M G_{j}+v_{j},
$$

where

$\hat{\mathrm{g}}$

$=$ estimates of relative wages, relative to the omitted metropolitan area, across each of 86 metropolitan areas, for men or women in a particular subpopulation;

MWG = an estimate of the metropolitan wage level in 1985, prior to the recent immigrants' arrival $^{5}$;

PIMG = the percentage of a metropolitan area's population that consists of recent immigrants (ones arriving between 1985 and 1990); and

$\mathrm{v}=\mathrm{a}$ randomly distributed error term.

The percentage of the population that is recent immigrants is calculated from Census data, by finding the 1990 proportion of people in each metropolitan area who were immigrants that entered the U.S. after 1984. This estimate might be an imprecise measure of immigration's impact on a metropolitan area's labor supply. The 1990 Census counted both legal and illegal immigrants, but illegal immigrants are probably undercounted. If rates of undercounting are higher in some metropolitan areas than others, then differences in the recent immigrant variable will measure differences in immigrants' contribution to the labor supply between metropolitan areas imprecisely. Unfortunately, there is no obvious way to adjust for differences in the rate of undercounting; the Census Bureau has no formal estimates of the number of undocumented immigrants it counted, either at the national or the metropolitan level (Goldfarb 1995).

The wage equation is estimated for 20 subpopulations of native workers, defined by sex, level of education, potential experience, or ethnicity. To explore other influences on metropolitan wages, subsequent estimations on the same subpopulations add two additional independent variables: a measure of shifts in labor demand and a measure of changes in metropolitan price levels.

\footnotetext{
5The estimates are based on regressions run on all individuals from sample metropolitan areas, using data from the Outgoing Rotation Groups of the CPS from 1985 and 1986. Log wages were regressed on highest grade attended, potential experience, and potential experience squared, along with dummies equal to one for women, Blacks, Hispanics, and for data from 1986. In addition, dummies were included for each of the metropolitan areas in the sample. Coefficients on these dummies form the estimates of metropolitan wage levels. Data from 1986 were included because only 49 metropolitan areas in the sample were identified in the 1985 CPS. Of the metropolitan coefficients, 53 of 85 were statistically significant in a two-tailed test at the $5 \%$ level.
} 


\section{ESTIMATING METROPOLITAN WAGE LEVELS}

This section discusses the estimation techniques, presents estimates of Equations 1 and 2, and evaluates the results of estimations in the context of prior research. To interpret the estimates, it may be helpful to review the variable means and standard deviations presented in Table 1.

TABLE 1

Variable Means and Standard Deviations

A. Variables Defined for Individuals

\begin{tabular}{lcccc} 
& \multicolumn{2}{c}{$\begin{array}{c}\text { Men } \\
\text { Standard } \\
\text { Deviation }\end{array}$} & Mean & $\begin{array}{c}\text { Women } \\
\text { Standard } \\
\text { Deviation }\end{array}$ \\
\hline LNWAGE & 2.44 & 0.76 & 2.12 & 0.69 \\
Less than a high school diploma & 0.18 & 0.38 & 0.14 & 0.35 \\
High school diploma & 0.30 & 0.46 & 0.34 & 0.47 \\
Some college, but no BA & 0.27 & 0.45 & 0.31 & 0.46 \\
BA & 0.16 & 0.37 & 0.15 & 0.36 \\
PEXP & 21.35 & 13.48 & 18.12 & 12.76 \\
BLK & 0.22 & 0.42 & 0.27 & 0.45 \\
HISP & 0.08 & 0.27 & 0.07 & 0.26 \\
OTH & 0.02 & 0.14 & 0.02 & 0.14 \\
N & 294,866 & & 276,336 & \\
\hline
\end{tabular}

B. Variables Defined for Metropolitan Areas

\begin{tabular}{lccc} 
Variable & Mean & $\begin{array}{c}\text { Standard } \\
\text { Deviation }\end{array}$ & $\mathrm{N}$ \\
\hline$\hat{\mathrm{g}}$ for men with no high school diploma & -0.004 & 0.133 & 86 \\
$\hat{\mathrm{g}}$ for women with no high school diploma & 0.012 & 0.124 & 86 \\
MWG & .006 & .082 & 86 \\
PIMG & .081 & 2.310 & 86 \\
Exogenous change in labor demand & 1.160 & .016 & 86 \\
Change in prices (measured by CPI) & 1.150 & .038 & 26 \\
Change in prices (measured by ACCRA index) & 1.015 & .062 & 51 \\
Change in population & 1.076 & .116 & 84
\end{tabular}

Note: Part A reports statistics for individual workers sampled. Because of the sampling strategy and because the statistics are unweighted, the statistics presented are not precise estimates of population parameters. The four educational categories do not add to one because they exclude people with more than a BA. Part B reports statistics for variables defined at the metropolitan level. Differences in the mean of the two price change variables reflect what they measure: the 1.15 for the Consumer Price Index (CPI) measure says the average city's price level rose 15 percent between 1985 and 1989, while the 1.015 for the American Chamber of Commerce Research Association (ACCRA) measure says the living cost of the average city in the sample rose 1.5 percent relative to the mean of all the ACCRA cities.

Table 2 presents a sample estimation of Equation 1, for men with less than a high school diploma. The potential experience coefficients predict that these men's wages reach their maximum around 41 years of age. Coefficients of the race/ethnicity variables suggest earnings disadvantages consistent with other research. Experience and race/ethnicity variables are easily statistically significant. Coefficients on the metropolitan dummy variables are statistically significant in 54 of 85 cases. The largest earnings deficit, relative to the omitted metropolitan area (Portland, Oregon) was 31 percent, in San Antonio, Texas. The largest earnings surplus was 27 percent, in Bergen-Passaic, New Jersey. 
TABLE 2

Estimating Equation 1, for Men with Less than a High School Diploma

\begin{tabular}{|c|c|c|c|c|c|}
\hline Variable & Coeff. & $t$ & Variable & Coeff. & $\mathrm{t}$ \\
\hline (Constant) & $1.568^{*}$ & 50.6 & Louisville, KY & $-0.146^{*}$ & 3.51 \\
\hline PEXP & $0.047^{*}$ & 66.9 & Memphis, TN-AR-MS & $-0.155^{*}$ & 4.13 \\
\hline PEXPSQ & $-0.001^{*}$ & 44.7 & Miami-Hialeah, FL & 0.059 & 0.99 \\
\hline BLK & $-0.176^{*}$ & 25.8 & Middlesex-Somerset, NJ & $0.219^{*}$ & 4.34 \\
\hline HISP & $-0.076^{*}$ & 6.52 & Milwaukee, WI & 0.008 & 0.23 \\
\hline OTH & $-0.041^{*}$ & 3.37 & Minneapolis-St. Paul, MN-WI & -0.058 & 1.41 \\
\hline Name of MSA or PMSA and State & & & Monmouth-Ocean, NJ & $0.210^{*}$ & 4.94 \\
\hline Akron, $\mathrm{OH}$ & -0.004 & 0.10 & Nashville-Davidson, TN & $-0.092^{*}$ & 2.45 \\
\hline Albany-Schenectady-Troy, NY & -0.005 & 0.11 & Nassau-Suffolk, NY & $0.238^{*}$ & 5.69 \\
\hline Anaheim-Santa Ana, CA & $0.174^{*}$ & 4.66 & New Haven-Meriden, CT & $0.197^{*}$ & 3.25 \\
\hline Atlanta, GA & 0.013 & 0.34 & New Orleans, LA & $-0.202^{*}$ & 4.80 \\
\hline Baltimore, MD & 0.064 & 1.92 & New York, NY & $0.166^{*}$ & 4.06 \\
\hline Bergen-Passaic, NJ & $0.275^{*}$ & 5.58 & Newark, NJ & $0.224^{*}$ & 4.11 \\
\hline Birmingham, $\mathrm{Al}$ & $-0.118^{*}$ & 2.97 & Norfolk-Virginia Beach, VA & 0.008 & 0.21 \\
\hline Boston, MA & $0.148^{*}$ & 4.50 & Oakland, CA & $0.221^{*}$ & 3.58 \\
\hline Buffalo, NY & -0.020 & 0.48 & Oklahoma City, OK & $-0.164^{*}$ & 3.83 \\
\hline Charleston, SC & $-0.130^{*}$ & 3.14 & Omaha, NE-IÁ & $-0.161^{*}$ & 2.85 \\
\hline Charlotte-Gastonia-Rock Hill & $-0.086^{*}$ & 2.40 & Orlando, FL & $-0.101^{*}$ & 2.30 \\
\hline Chicago, IL & $0.083^{*}$ & 2.00 & Oxnard-Ventura, CA & $0.170^{*}$ & 3.73 \\
\hline Cincinnati, OH-KY-IN & -0.042 & 1.11 & Philadelphia, PA & $0.084^{*}$ & 2.40 \\
\hline Cleveland, $\mathrm{OH}$ & 0.053 & 1.33 & Phoenix, AZ & $-0.126^{*}$ & 3.21 \\
\hline Columbus, $\mathrm{OH}$ & $-0.133^{*}$ & 3.54 & Pittsburgh, PA & -0.067 & 1.69 \\
\hline Dallas, TX & $-0.117^{*}$ & 2.57 & Providence, RI & -0.056 & 0.90 \\
\hline Dayton-Springfield, $\mathrm{OH}$ & $-0.078^{*}$ & 1.86 & Raleigh-Durham, NC & $-0.113^{*}$ & 2.68 \\
\hline Denver, CO & -0.039 & 0.91 & Richmond-Petersburg, VA & -0.018 & 0.46 \\
\hline Detroit, MI & $0.144^{*}$ & 4.08 & Riverside-San Bernardino, CA & $0.130^{*}$ & 3.44 \\
\hline El Paso, TX & $-0.280^{*}$ & 6.71 & Rochester, NY & -0.002 & 0.05 \\
\hline Fort Lauderdale-Hollywood, Fl & 0.002 & 0.04 & Sacramento, CA & 0.057 & 1.25 \\
\hline Fort Worth-Arlington, TX & $-0.087^{*}$ & 2.04 & St. Louis, MO-IL & -0.009 & 0.26 \\
\hline Fresno, CA & $-0.086^{*}$ & 2.13 & Salt Lake City-Ogden, UT & $-0.156^{*}$ & 3.25 \\
\hline Gary-Hammond, IN & $0.102^{*}$ & 2.28 & San Antonio, TX & $-0.309^{*}$ & 7.80 \\
\hline Grand Rapids, MT & 0.021 & 0.45 & San Diego, CA & 0.077 & 1.91 \\
\hline Greensboro-Winston-Salem, NC & $-0.098^{*}$ & 2.66 & San Francisco, CA & $0.134^{*}$ & 2.51 \\
\hline Greenville-Spartanburg, SC & $-0.171^{*}$ & 4.33 & San Jose, CA & $0.219^{*}$ & 5.01 \\
\hline Harrisburg-Lebanon, PA & $-0.078^{*}$ & 1.72 & Scranton-Wilkes-Barre, PA & $-0.105^{*}$ & 2.06 \\
\hline Hartford, CT & $0.157^{*}$ & 2.98 & Seattle, WA & 0.085 & 1.86 \\
\hline Honolulu, HI & $0.125^{*}$ & 2.93 & Springfield, MA & 0.034 & 0.64 \\
\hline Houston, TX & -0.070 & 1.66 & Syracuse, NY & $-0.113^{*}$ & 2.48 \\
\hline Indianapolis, IN & -0.061 & 1.62 & Tacoma, WA & 0.087 & 1.72 \\
\hline Jacksonville, FL & $-0.077^{*}$ & 1.90 & Tampa-St. Petersburg, FL & $-0.162^{*}$ & 4.20 \\
\hline Jersey City, NJ & $0.211^{*}$ & 4.54 & Toledo, $\mathrm{OH}$ & -0.083 & 1.82 \\
\hline Kansas City, MO-KS & $-0.069^{*}$ & 1.81 & Tucson, AZ & $-0.189^{*}$ & 4.31 \\
\hline Knoxville, TN & $-0.234^{*}$ & 5.50 & Tulsa, OK & $-0.185^{*}$ & 3.99 \\
\hline Lake County, IL & 0.019 & 0.34 & Washington, DC-MD-VA & $0.118^{*}$ & 2.68 \\
\hline Las Vegas, NV & -0.005 & 0.13 & West Palm Beach-Boca Rtn., FL & -0.044 & 1.07 \\
\hline Los Angeles-Long Beach, CA & $0.147^{*}$ & 3.75 & Wilmington, DE-NJ-MD & 0.046 & 0.95 \\
\hline
\end{tabular}

Note: All the variables listed after experience variables are dummies. Coefficients on the metropolitan dummy variables became metropolitan wage measures for this group in the second stage of the estimation process. Names for the metropolitan areas are for the Metropolitan Statistical Area (MSA) or the Primary Metropolitan Statistical Area (PMSA), whichever is relevant. In this and subsequent tables, an asterisk indicates a coefficient that is significantly different from zero in a two-tailed test, with a $5 \%$ confidence interval. Also, because heteroscedasticity may be present, all the $t$-statistics presented here and subsequently are computed using White's method. 
All the estimates presented are ordinary least squares. Some authors have found evidence for immigration being endogenous, for immigrants tending to locate in high-wage cities. In this case, however, a Hausman test found evidence for endogeneity in only one of 20 subpopulations. $^{6}$

Table 3 presents a sample estimation of Equation 2, first for men with less than a high school diploma and then for women in the same educational group. The same independent variables were used to estimate metropolitan wage levels for the 18 other subpopulations. The discussion of the results for the control variable includes all 20 estimations.

TABLE 3

Estimating Wage Levels for Workers with Less than High School Education

\begin{tabular}{|c|c|c|c|c|}
\hline \multirow[b]{2}{*}{ Variable } & \multicolumn{2}{|c|}{ Men } & \multicolumn{2}{|c|}{ Women } \\
\hline & Coefficient & t-statistic & Coefficient & t-statistic \\
\hline Constant & $-0.028^{*}$ & 2.05 & -0.016 & 1.17 \\
\hline MWG & $1.101^{*}$ & 6.95 & $0.937^{*}$ & 6.51 \\
\hline PIMG & 0.007 & 1.72 & $0.013^{*}$ & 2.31 \\
\hline $\mathrm{R}^{2}$ & 0.58 & & 0.62 & \\
\hline F-statistic & 56.88 & & 68.03 & \\
\hline
\end{tabular}

Note: These are the results from the second-stage regression for men and women. The dependent variable for the men's regression is the metropolitan wage measure created from the coefficients of the metropolitan dummy variables presented in Table 2 .

These results suggest, first, that it is important to control for prior wage levels in a metropolitan area. The magnitude of the coefficients for the metropolitan wage level variable in Table 3 suggests considerable persistence of wage levels between 1985 and 1989. This result is consistent with estimations for the other subpopulations: the mean value of the coefficient across the 20 subpopulations is .93 and, in all but one subpopulation, the coefficient is statistically significant. This mean value suggests that a one standard deviation rise in the 1985 wage level ( 8.2 $\log$ points) is associated with, on average, a $7.6 \log$ point rise in the wage level in 1989. This persistence could result, for example, from persistent differences in living costs and/or from local amenities affecting labor supply.?

The variable of interest for this study is recent immigration into a metropolitan area. Table 4 shows the coefficients of the recent immigration variable from estimations of Equation 2 for 20 subpopulations. Subpopulations were selected based on their interest for the study, but also based on group size. For example, there were not enough inexperienced high school dropouts to get reliable estimates of their metropolitan wage levels, so dropouts were combined with workers who had a high school diploma to form a group of inexperienced, less-educated workers.

${ }^{6}$ Three instruments were used in the test: a) foreign-born as a proportion of metropolitan population in 1980; b) employment growth in the state, 1975-85; and c) the unemployment rate in 1985 . Differences between the OLS results presented and 2SLS regressions run for purposes of comparison were small; the mean coefficient for the immigration variable in the OLS regressions was on average 5 percent bigger than the mean coefficient in 2SLS regressions.

7 See Dumond, Hirsch, and MacPherson (1999) for a careful discussion of alternative approaches to understanding the characteristics of metropolitan areas and how those characteristics might affect both price and wage levels. 
TABLE 4

Coefficients of PIMG for Different Subpopulations

\begin{tabular}{lcccc}
\hline & \multicolumn{2}{c}{ Men } & \multicolumn{2}{c}{ Women } \\
Education/Experience Group & Coefficient & t-statistic & Coefficient & t-statistic \\
\hline Less than a high school diploma & 0.007 & 1.72 & $0.013^{*}$ & 2.31 \\
High school diploma & 0.002 & 0.60 & $0.016^{*}$ & 3.83 \\
Some college & 0.004 & 1.19 & $0.018^{*}$ & 5.07 \\
BA & 0.003 & 0.87 & $0.017^{*}$ & 4.62 \\
Inexperienced, less educated & $0.014^{*}$ & 2.89 & $0.019^{*}$ & 3.52 \\
Inexperienced, college educated & $0.012^{*}$ & 2.84 & $0.015^{*}$ & 3.68 \\
Black, less educated & 0.004 & 0.85 & 0.010 & 1.82 \\
Black, college educated & $0.011^{*}$ & 2.20 & $0.012^{*}$ & 3.73 \\
Hispanic, less educated & -0.001 & 0.17 & $0.009^{*}$ & 2.06 \\
Other, less educated & 0.008 & 1.00 & 0.011 & 1.87 \\
\hline
\end{tabular}

The results from these regressions are consistent with estimates in prior studies on 1980s data that omit area fixed effects. They provide no evidence that immigration lowers wages for any of the subpopulations studied, even groups that might have been thought to be at special risk: low-education workers, inexperienced workers, or workers of color. No coefficient is negative and statistically significant. Moreover, the coefficient is positive and statistically significant in 11 of the 20 subpopulations.

It is difficult to explain these positive coefficients on a variable measuring immigration. Some suggest that well-educated workers are complements to immigrants in most production processes, while less-educated natives are substitutes. Taken at face value, the evidence here suggests broadly positive effects on native workers, with no tendency for low-education natives - even people of color-to do worse than other workers in cities with many recent immigrants. ${ }^{8}$

To see if this phenomenon might result from omitted variable bias, two additional sets of regressions were estimated. The first set added a measure of labor demand shifts over the study period; the second set added a measure of changes in metropolitan price levels.

The demand shift variable is an estimate of exogenous changes in labor demand in each metropolitan area similar to one used by Bound and Holzer (2000). ${ }^{9}$ Equation 2 was reestimated with the new variable added. This first set of additional regressions is not presented; the coefficients for the immigration measure are practically indistinguishable from those presented in Table 3. Averaged across the 20 subpopulations, adding the change in labor demand variable to the model reduced the coefficient of the recent immigration variable, but by less than 1 percent.

8In a study restricted to male workers, Enchautegui (1995) gets a similar result and accepts it at face value. She says that non-Hispanic white men and African American men both made bigger wage gains between 1980 and 1990 in "areas of high and medium immigration than did their counterparts in areas of low immigration" (p. 34). ${ }^{9}$ To estimate the exogenous change in labor demand for a metropolitan area, one begins with a row vector containing the proportion of metropolitan employment in each of 33 industries in 1986. That vector is then multiplied by a column vector containing proportional changes in employment from 1986 to 1989, across all metropolitan areas, for the same 33 industries. The result gives the projected employment growth from 1986 to 1989 , based on the area's industry structure of employment in 1986. The year 1986 is used (rather than 1985) because of the limited group of metropolitan areas identified in the 1985 CPS. 
One might take these results as strong evidence against the hypothesis that areas with high levels of immigration benefited from shifts in the industry composition of labor demand. However, that would be a mistake, since the coefficient of the labor demand variable was statistically significant in only 5 of the 20 subpopulations. This contrasts with the results of Bound and Holzer (2000), for whom coefficients on the labor demand measure in wage equations were significant in 25 of 28 subpopulations. To make strong statements about the impact of omitting controls for labor demand from studies of immigration's impact, one would first like to see convincing evidence that the labor demand measure used consistently captured an important influence on wages.

Even so, the results of these additional regressions suggest that controlling for exogenous shifts in labor demand helps one understand metropolitan wage levels, at least for women. The coefficient on the labor demand shift variable was positive and statistically significant in five of the ten female subpopulations, especially for subpopulations including less-educated or Black workers. ${ }^{10}$ For these subpopulations, at least, metropolitan areas with larger increases in labor demand between 1986 and 1989 tended to have somewhat higher wages in 1989.

The second set of additional regressions adds metropolitan inflation rates to a model estimated with controls for the prior wage level and for shifts in labor demand. This approach allows one to investigate the relationship between rises in nominal wages and rises in living costs. Two measures of changes in metropolitan price levels are used. The first measure uses the Consumer Price Index (CPI), while the second uses cost-of-living data from the American Chamber of Commerce Research Association (ACCRA). ${ }^{11}$

The results with both measures suggest that rises in living costs had an important influence on 1989 wage levels. On average, a 10 percent rise in the price measure was associated with a 12 percent rise in nominal wages for the CPI data (in a sample of 26 cities with data available) and with an 8 percent rise in nominal

${ }^{10}$ In descending order of coefficient size, the female subpopulations with statistically significant coefficients were Black, less-educated; less than a high school diploma; Black, college-educated; high school diploma; and some college. For Black, less-educated women, a one standard deviation rise in labor demand (1.6 percent) was associated with a 2.5 percent rise in their wage level. In general, for women and for men, Black subpopulations have larger coefficients than the corresponding subpopulations of all workers, and less-educated subpopulations have larger coefficients than subpopulations with more education. These patters also appear in Bound and Holzer's $(2000)$ results. The tendency for industry mix to matter more for women than men is consistent with Easton and King's (2000) findings.

${ }^{11}$ The first measure computes the price level change at the metropolitan level using the CPI for All Urban Consumers. Data were taken from the CPI Detailed Report, January 1986, pp. 103-111, and January 1990, pp. 186-201. Metropolitan CPIs are not reliable estimates of differences in living costs among metropolitan areas in a given year; however, they are reliable estimates of differences in inflation rates. The second measure uses ACCRA's allitems index from the fourth quarter of 1986 and 1989. For a small number of cities, however, data were not available in the fourth quarter, but were available in the third. For these cities, fourth quarter values were projected using a regression estimating fourth quarter values of the index with third quarter values. Data for 1985 were taken from the Inter-City Cost of Living Index for the third and fourth quarters, Section 2, pp. 1-4. Data for 1989 were taken from the Cost of Living Index, pp. 1.1 to 1.11 for the third quarter and pp. 2.1 to 2.5 for the fourth quarter. The ACCRA index measures cross section differences in living costs among cities for a particular quarter, for the cities included in the index that quarter. It is not designed to measure changes in living costs over time. Estimating change in the CPI with change in the ACCRA index, for the 18 cities with both CPI and ACCRA data available, the $R^{2}$ is .46 and the t-statistic on the ACCRA coefficient is 3.72 . 
wages for the ACCRA data (in a sample of 51 cities). The coefficients on the price change variables are presented in Table 5 . They are statistically significant in 39 out of 40 regressions.

\section{TABLE 5}

Coefficient for Change in Metropolitan Price Level, CPI Sample \& ACCRA Sample

\begin{tabular}{lcccc}
\hline A) Men & \multicolumn{2}{c}{$\begin{array}{c}\text { CPI Price Change Measure } \\
\text { Coefficient }\end{array}$} & $\begin{array}{c}\text { ACCRA Price Change Measure } \\
\text { t-statistic }\end{array}$ & $\begin{array}{c}\text { Coefficient } \\
\text { t-statistic }\end{array}$ \\
\hline Less than a high school diploma & $1.532^{*}$ & 4.772 & $0.929^{*}$ & 5.026 \\
High school diploma & $1.398^{*}$ & 4.736 & $0.817^{*}$ & 4.969 \\
Some college & $1.459^{*}$ & 8.634 & $0.723^{*}$ & 5.698 \\
BA & $1.168^{*}$ & 4.003 & $0.472^{*}$ & 2.693 \\
Inexperienced, less educated & $1.116^{*}$ & 2.734 & $0.788^{*}$ & 3.999 \\
Inexperienced, college educated & $1.433^{*}$ & 5.190 & $0.772^{*}$ & 4.414 \\
Black, less educated & $0.749^{*}$ & 1.867 & $0.863^{*}$ & 4.486 \\
Black, college educated & 0.611 & 1.341 & $0.620^{*}$ & 3.589 \\
Hispanic, less educated & $1.659^{*}$ & 3.793 & $1.061^{*}$ & 2.587 \\
Other, less educated & $1.831^{*}$ & 3.085 & $1.081^{*}$ & 2.885
\end{tabular}

\begin{tabular}{lcccc}
\hline B) Women & $\begin{array}{c}\text { CPI Price Change Measure } \\
\text { Coefficient }\end{array}$ & $\begin{array}{c}\text { ACCRA Price Change Measure } \\
\text { t-statistic }\end{array}$ & $\begin{array}{c}\text { Coefficient } \\
\text { t-statistic }\end{array}$ \\
\hline Less than a high school diploma & $1.455^{*}$ & 6.408 & $0.958^{*}$ & 6.352 \\
High school diploma & $1.252^{*}$ & 6.391 & $0.687^{*}$ & 4.619 \\
Some college & $0.973^{*}$ & 4.223 & $0.645^{*}$ & 3.695 \\
BA & $1.355^{*}$ & 5.670 & $0.472^{*}$ & 2.693 \\
Inexperienced, less educated & $1.413^{*}$ & 5.155 & $0.788^{*}$ & 3.999 \\
Inexperienced, college educated & $1.316^{*}$ & 4.578 & $0.625^{*}$ & 3.594 \\
Black, less educated & $1.409^{*}$ & 3.119 & $1.016^{*}$ & 4.698 \\
Black, college educated & $1.096^{*}$ & 3.756 & $0.707^{*}$ & 3.850 \\
Hispanic, less educated & $1.165^{*}$ & 3.125 & $0.980^{*}$ & 3.344 \\
Other, less educated & $0.953^{*}$ & 2.499 & $1.265^{*}$ & 3.598
\end{tabular}

Note: The four columns report coefficients and t-statistics for measures of the change in the metropolitan price level from equations estimating 1989 wage levels for various groups. The measures were included in an estimation of Equation 2 that also included the change in labor demand as an independent variable. The first column reports coefficients for the change in the price level measured with the CPI; the coefficient for PIMG in these regressions is reported in Column 3 of Table 6. The third column reports the coefficients of the change in the price level measured by ACCRA; the coefficient for PIMG in these regressions is reported in Column 3 of Table 7.

Table 6 presents the coefficients of the recent immigration variable from the regressions using the CPI measure of change in the price level, preceded by the coefficient of the immigration variable from an estimation of the metropolitan wage level for the same 26-city sample, but without the price level control. The results suggest that controlling for inflation substantially reduces the size of the anomalous positive coefficients on the variable measuring recent immigration. Controlling for inflation reduces the coefficient of the immigration variable by an average of .008 ( 138 percent for men and 88 percent for women). In only four cases out of 20 regressions is the coefficient still positive and statistically significant after the change.

Coefficients of the immigration variable for estimations of the wage level utilizing the ACCRA measure of changes in the price level are presented in Table 7. The third column shows coefficients for estimations of wages in 1989 with the ACCRA measure included among the independent variables, while the first column shows estimations for the same sample of 51 cities, but without a control for 
changes in the price level. Even more than the results presented in Table 6, these results suggest that the anomalous positive coefficients on the immigration measure result from omitting an inflation control. Adding the ACCRA price measure reduces the immigration coefficient by an average of .016 , twice the size of the reduction in Table 6. After the control for changes in the price level is added, there are four statistically significant, positive coefficients in Table 6 , but only one in Table 7.

TABLE 6

Effect of Inflation Control on Coefficients of PIMG, CPI Sample

\begin{tabular}{lcccc}
\hline A) Men & \multicolumn{2}{c}{$\begin{array}{c}\text { Without Inflation Control } \\
\text { Coefficient }\end{array}$} & $\begin{array}{c}\text { With Inflation Control } \\
\text { t-statistic }\end{array}$ & $\begin{array}{c}\text { Coefficient } \\
\text { t-statistic }\end{array}$ \\
\hline Less than a high school diploma & $0.013^{*}$ & 2.78 & 0.004 & 1.01 \\
High school diploma & 0.006 & 1.58 & -0.003 & 0.54 \\
Some college & $0.008^{*}$ & 2.11 & 0.000 & 0.18 \\
BA & $0.008^{*}$ & 2.35 & 0.001 & 0.21 \\
Inexperienced, less educated & $0.011^{*}$ & 2.25 & 0.004 & 0.62 \\
Inexperienced, college educated & $0.009^{*}$ & 2.93 & 0.000 & 0.02 \\
Black, less educated & 0.006 & 1.52 & 0.001 & 0.23 \\
Black, college educated & $0.014^{*}$ & 2.17 & 0.011 & 1.16 \\
Hispanic, less educated & 0.006 & 1.31 & -0.004 & 0.51 \\
Other, less educated & $0.012^{*}$ & 2.18 & 0.001 & 0.05 \\
\hline B) Women & Without Inflation Control & With Inflation Control \\
& Coefficient & t-statistic & Coefficient & t-statistic \\
\hline Less than a high school diploma & 0.009 & 1.04 & 0.000 & 0.05 \\
High school diploma & $0.015^{*}$ & 3.31 & $0.007^{*}$ & 3.63 \\
Some college & $0.020^{*}$ & 7.60 & $0.014^{*}$ & 4.09 \\
BA & $0.015^{*}$ & 3.51 & $0.007^{*}$ & 2.21 \\
Inexperienced, less educated & $0.015^{*}$ & 2.98 & $0.006^{*}$ & 2.15 \\
Inexperienced, college educated & $0.015^{*}$ & 3.77 & 0.007 & 1.68 \\
Black, less educated & 0.007 & 1.05 & -0.001 & 0.42 \\
Black, college educated & $0.012^{*}$ & 3.50 & 0.006 & 1.47 \\
Hispanic, less educated & $0.011^{*}$ & 3.02 & 0.003 & 0.66 \\
Other, less educated & 0.006 & 0.97 & 0.000 & 0.04 \\
\hline
\end{tabular}

Note: For these regressions, the sample is the 26 metropolitan areas for which changes in the metropolitan CPI can be calculated. The first two columns of statistics are taken from estimations of Equation 2, with a third independent variable added: the change in labor demand from 1986 to 1989. The second two columns add a fourth independent variable: the CPI measure of the change in the metropolitan price level between 1985 and 1989.

Using two different measures of inflation and two different samples of cities, Tables 6 and 7 explore the importance of controlling for inflation for those who wish to measure immigration's impact on wages. Both tables lead one to the same conclusion: some of the mysterious rise in nominal wages in high-immigration cities resulted from rising living costs. ${ }^{12}$

Nonetheless, the results reported in these tables offer an incomplete explanation of the mystery. Even after controlling for changes in the metropolitan price level, some groups of native workers that one would expect to compete strongly

\footnotetext{
12Because it suggests living costs are an important omitted variable in prior studies of immigration's impact on wages, this study shares an important theme with a recent paper by Dumond, Hirsch, and MacPherson (1999). They discovered that omitting a living cost measure biases one's measure of racial and ethnic earnings differentials in the United States. Black/White, Hispanic/non-Hispanic, and Asian/White earnings differentials all grow substantially when one adds a control for metropolitan living costs.
} 
with recent immigrants have positive coefficients on the immigration variable, especially in Table 6. Since one of the largest groups of employed recent immigrants are men with less than a high school diploma ( 25 percent of all recent immigrants included in this study), one such group would be native men in the same education category. One way to further explore the mystery is to identify which cities exhibit it in strong form, that is, cities with large populations of recent immigrants and higher wages than expected or small populations of recent immigrants and lower wages than expected. Identifying such cities may suggest hypotheses to guide future investigations of the mystery.

TABLE 7

Effect of Inflation Control on Coefficients of PIMG, ACCRA Sample

\begin{tabular}{lcccc}
\hline A) Men & \multicolumn{2}{c}{ Without Inflation Control } & \multicolumn{2}{c}{ With Inflation Control } \\
& Coefficient & t-statistic & Coefficient & t-statistic \\
\hline Less than a high school diploma & -0.001 & 0.07 & -0.013 & 1.61 \\
High school diploma & -0.003 & 0.47 & $-0.019^{*}$ & 4.47 \\
Some college & -0.003 & 0.37 & $-0.015^{*}$ & 2.83 \\
BA & -0.002 & 0.28 & -0.014 & 1.88 \\
Inexperienced, less educated & 0.009 & 1.00 & 0.006 & 0.91 \\
Inexperienced, college educated & 0.008 & 0.91 & -0.007 & 1.03 \\
Black, less educated & -0.003 & 0.20 & -0.021 & 1.50 \\
Black, college educated & 0.007 & 0.70 & -0.008 & 0.84 \\
Hispanic, less educated & -0.022 & 1.53 & $-0.047^{*}$ & 2.79 \\
Other, less educated & -0.007 & 0.29 & -0.036 & 1.49 \\
\hline B) Women & Without Inflation Control & With Inflation Control \\
& Coefficient & t-statistic & Coefficient & t-statistic \\
\hline Less than a high school diploma & 0.017 & 1.81 & 0.002 & 0.19 \\
High school diploma & 0.007 & 0.84 & -0.006 & 0.79 \\
Some college & 0.008 & 0.87 & -0.007 & 0.95 \\
BA & $0.020^{*}$ & 4.67 & $0.017^{*}$ & 3.38 \\
Inexperienced, less educated & 0.009 & 0.74 & -0.013 & 1.18 \\
Inexperienced, college educated & 0.003 & 0.47 & -0.009 & 1.19 \\
Black, less educated & 0.007 & 0.50 & -0.011 & 0.77 \\
Black, college educated & 0.010 & 1.35 & -0.006 & 1.21 \\
Hispanic, less educated & 0.002 & 0.15 & -0.021 & 1.48 \\
Other, less educated & 0.017 & 1.42 & -0.002 & 0.22 \\
\hline
\end{tabular}

Note: For these regressions, the sample is the 55 metropolitan areas for which price changes could be constructed using ACCRA data. The first two columns of statistics are taken from estimations of Equation 2, with a third independent variable added: the change in labor demand from 1986 to 1989. The second two columns add a fourth independent variable: a measure of the change in the metropolitan price level between 1985 and 1989.

Table 8 aids in this identification by presenting the names of the metropoli$\tan$ areas with CPI data, the proportion of the population that is recent immigrants for each area, and the residual for a wage equation predicting the wage level for men with less than a high school diploma. Cities with small populations of recent immigrants and lower-than-expected wages include Minneapolis, Kansas City, Dallas, and Chicago. Cities with large populations of recent immigrants and higherthan-expected wages include Miami, Los Angeles, and San Francisco. If one estimates the wage level of men with less than a high school diploma, removing these cities (from either the CPI sample or the ACCRA sample) turns the coefficient of the immigration variable negative and statistically significant. 
TABLE 8

Residual and Proportion of Recent Immigrants

\begin{tabular}{lcc}
\hline Name \& State of Metropolitan Area & PIMG & Residual \\
\hline Minneapolis-St. Paul, MN-WI & 1.1 & -8.3 \\
Dallas, TX & 3.0 & -8.2 \\
Kansas City, MO-KS & 0.5 & -7.2 \\
Chicago, IL & 3.2 & -5.5 \\
Cincinnati, OH-KY-IN & 0.5 & -3.2 \\
Atlanta, GA & 1.7 & -2.8 \\
Pittsburgh, PA & 0.4 & -2.7 \\
New York, NY & 7.4 & -2.5 \\
St. Louis, MO-IL & 0.5 & -1.1 \\
San Diego, CA & 5.1 & -0.6 \\
Houston, TX & 3.3 & -0.6 \\
Portland, OR & 1.8 & -0.3 \\
Washington, DC-MD-VA & 4.9 & -0.1 \\
Honolulu, HI & 4.5 & 0.3 \\
Boston, MA & 3.8 & 0.6 \\
Milwaukee, WI & 0.7 & 1.5 \\
Los Angeles-Long Beach, CA & 10.2 & 1.7 \\
Philadelphia, PA & 1.3 & 1.7 \\
Buffalo, NY & 1.0 & 2.1 \\
Baltimore, MD & 0.8 & 2.7 \\
Denver, CO & 1.2 & 3.0 \\
San Francisco, CA & 6.7 & 3.6 \\
Cleveland, OH & 0.7 & 4.4 \\
Miami-Hialeah, FL & 10.0 & 5.3 \\
Detroit, MI & 0.8 & 7.8 \\
Seattle, WA & 2.1 & 8.4
\end{tabular}

Note: Column 1 reports the names of the 26 metropolitan areas with data to calculate the CPI change in price level measure. Column 2 shows the estimated proportion of the population of each metropolitan area that was recent immigrants in 1990. Column 3 shows the residual of the equation estimating wage levels for men with a less than a high school diploma, with MWG and change in labor demand included as independent variables. Metropolitan areas are sorted, with the smallest residuals presented first.

If rises in nominal wages in high-immigration cities were associated with higher price levels in these cities, it would be important to ask why. In particular, one might wonder if immigration could cause rising price levels. For example, perhaps population grows faster in cities that have more immigration (as suggested by Card 1997, 2001). If that were true, faster increases in the cost of shelter, and in living costs in general, could result.

Other research lends some additional plausibility to this hypothesis about immigration, population growth, and living costs. First, living costs differences among metropolitan areas may have been growing in the 1980s. Eberts and Schweitzer (1994) found that, in a sample of 22 large metropolitan areas, the variance among consumer price indexes increased steadily between the early 1980s and the early 1990s. Second, about 90 percent of the differences in living costs among those areas were due to differences in the cost of shelter.

However, the data examined for this study suggest that rises in living costs did not result from immigration contributing to population growth and rising costs of shelter. Though there is a moderate correlation between recent immigration and population growth over the study period for the metropolitan areas with 
price level data, there is no correlation at all between population growth and the rise in living costs in those metropolitan areas. ${ }^{13}$

This study has explored omitted variable bias as an explanation for a positive correlation between immigration and wages in U.S. labor markets. A second possible explanation (albeit partial) for these results could be nonlinearities in immigration's effects on metropolitan areas. Enchautegui (1995) found evidence, for some subpopulations, that increases in immigration were associated with rises in metropolitan wage levels only up to a point. However, when the immigration variable in this study was squared and added to the regressions reported in Table 3 , in only one case out of 20 was the added variable's coefficient negative and statistically significant.

\section{CONCLUSIONS}

This paper estimates 1989 wage levels for various subpopulations of workers in a sample of the 86 largest metropolitan areas, seeking evidence for the effect of international migration into the United States on the wages of native workers. Estimations presented, like those by other authors for the 1980s without area fixed effects, find evidence for higher wage levels in metropolitan areas with higher levels of immigration.

To enhance our understanding of this surprising finding, this research provides estimates of metropolitan wage levels that control for other metropolitan characteristics besides immigration. Controls for shifts in the industrial structure of labor demand explain little of the rise in wage levels in high-immigration cities. On the other hand, controls for differences in inflation rates explain a large share of the rise in two subsamples for which changes in the price level can be estimated. This finding suggests that further research into the causes of changes in metropolitan living costs, and into the effect of changed living costs on nominal wages, is in order. It also suggests that researchers should not assume that results of studies using nominal wages as a dependent variable would also hold for real wages.

Although this research succeeds in explaining a good deal of the rise in living costs in high immigration cities, the success is not complete. Even with controls for changes in labor demand and living costs, some of the mysterious positive relationship between immigration into a metropolitan area and metropolitan wage levels remains.

\section{REFERENCES}

Altonji, J., and D. Card. "The Effects of Immigration on the Labor Market Outcomes of Less-skilled Natives." In J. Abowd and R. Freeman (eds.) Immigration, Trade, and the Labor Market. Chicago: University of Chicago Press, 1991.

${ }^{13}$ For the 26 cities with CPI data, the immigration-population correlation was .31 and the population-price correlation was -.005 . For the ACCRA cities, the same correlations were .32 and .04 . For the 84 metropolitan areas for which there are comparable population data in 1985 and 1990, the correlation between recent immigration and population growth is much weaker (.06). Population data are from U.S. Department of Commerce (1987, 1991). 
Borjas, G. "The Economics of Immigration." Journal of Economic Literature 32 (1994), 1667-1717.

Borjas, G., R. Freeman, and L. Katz. "Searching for the Effect of Immigration on the Labor Market." American Economic Review 86 (1996), 246-251.

. "How Much Do Immigration and Trade Affect Labor Market Outcomes?" Brookings Papers on Economic Activity, 1997, no. 1, 1-90.

Bound, J., and H. Holzer. "Demand Shifts, Population Adjustments, and Labor Market Outcomes During the 1980s." Journal of Labor Economics 18 (2000), 20-54.

Card, D. "The Impact of the Mariel Boatlift on the Miami Labor Market." Industrial \& Labor Relations Review 43 (2) (1990), 245-247.

"Immigrant Inflows, Native Outflows, and the Local Labor Market Impacts of Higher Immigration." National Bureau of Economic Research Working Paper 5927. Cambridge, MA, 1997.

"Immigrant Inflows, Native Outflows, and the Local Labor Market Impacts of Higher Immigration." Journal of Labor Economics 19 (2001), 22-64.

Dickens, W.T., and L.F. Katz. "Inter-Industry Wage Differences and Industry Characteristics." In K. Lang and J. S. Leonard (eds.) Unemployment and the Structure of Labor Markets. New York: Blackwell, 1987.

Dumond, M., B. Hirsch, and D. MacPherson. "Wage Differentials Across Labor Markets and Workers: Does Cost of Living Matter?" Economic Inquiry 37 (1999), 577-598.

Easton, T., and M. King. "Differences in Wage Levels Among Metropolitan Areas: Less-Educated Workers in the United States." Regional Studies 34 (2000), 21-27.

Eberts, R., and M. Schweitzer. "Regional Wage Convergence and Divergence: Adjusting Wages for Cost-of-Living Differences." Federal Reserve Bank of Cleveland Economic Review 30 (2) (1994), 26-36.

Eberts, R., and J. Stone. Wage and Employment Adjustment in Local Labor Markets. Kalamazoo, MI : W.E. Upjohn Institute, 1992.

Enchautegui, M. "Effects of Immigrants on the 1980-1990 U.S. Wage Experience." Contemporary Economic Policy 13 ( 3) (1995), 20-38.

Goldfarb, C. "Allocating the Local Apportionment Pie: What Portion for Resident Aliens?" The Yale Law Journal 104 (1995), 1441-1462.

Graves, P., R. Sexton, and M. Arthur. "Amenities and Fringe Benefits: Omitted Variable Bias." American Journal of Economics and Sociology 58 (3) (1999), 399-404.

Moulton, B. "Random Group Effects and the Precision of Regression Estimates." Journal of Econometrics 32 (3) (1986), 385-397.

U.S. Department of Commerce. Bureau of the Census. Statistical Abstract of the United States. Table 34. Washington, D.C.: General Printing Office, 1987. . Statistical Abstract of the United States. Table 36. Washington, D.C.: General Printing Office, 1991. 
